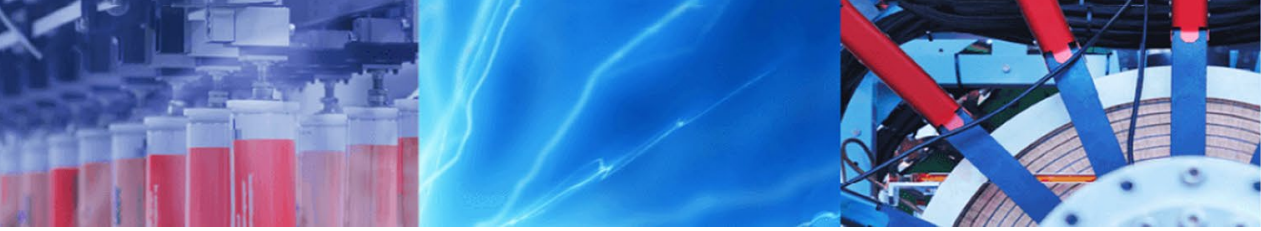

Research Article

\title{
Diffusion bonding of a titanium alloy to austenitic stainless steel using copper as an interlayer
}

\author{
A. Arun Negemiya ${ }^{1} \cdot$ S. Rajakumar ${ }^{1}$ (D) V. Balasubramanian ${ }^{1}$
}

(c) Springer Nature Switzerland AG 2019

\begin{abstract}
Diffusion bonding was accomplished between Ti-6AI-4V alloy and AISI 304 austenitic stainless steel utilizing copper as an interlayer in the holding time variety of $45-105 \mathrm{~min}$ for $925^{\circ} \mathrm{C}$ under $14 \mathrm{MPa}$ load in a vacuum. After bonding, the microstructural study including metallographic examination and energy dispersive spectroscopy, microhardness survey, lap shear strength test, and ram tensile test were accomplished. From the results, holding time is a major influence to develop the microstructural characteristics and improve the joints quality. The occasion of various intermetallic compounds, for example, $\mathrm{CuTi}, \mathrm{Cu}_{3} \mathrm{Ti}_{2}, \mathrm{FeTi}_{2}, \mathrm{Fe}_{2} \mathrm{Ti}_{1} \mathrm{Cr}_{2} \mathrm{Ti}_{\text {has }}$ been expected from the ternary phase diagrams of $\mathrm{Fe}-\mathrm{Cu}-\mathrm{Ti}$ and $\mathrm{Fe}-\mathrm{Cr}$-Ti. These reaction items were insisted on the X-ray diffraction method. The highest bond strength of $268 \mathrm{MPa}$ was attained for the pair bonded at $90 \mathrm{~min}$ holding time. This is a direct result of the better combination of the mating surface. With the expansion in holding time to $105 \mathrm{~min}$, the quality was reduced caused by the expanded volume fraction of discontinuities.
\end{abstract}

Keywords Diffusion bonding $\cdot$ Ti-6Al-4V alloy $\cdot$ Austenitic stainless steel $\cdot$ Holding time

\section{Introduction}

Titanium is a lightweight metal with the best strengthto-weight ratio of any metal and has exceptional erosion protection. Since titanium alloys are expensive, production processes aim at eliminating material wastage as much as possible. Above $890^{\circ} \mathrm{C}$, titanium undergoes an allotropic transformation to a body-centered cubic ' $\beta$ ' phase, which remains stable up to the melting point. Some alloying elements raise the alpha-to-beta transition temperature ( $a$-stabilizers) while others lower the transition temperature ( $\beta$-stabilizers). Aluminium, gallium, germanium, carbon, oxygen, and nitrogen are alpha stabilizers. Aluminium is the most widely alloyed alpha stabilizing element as it increases tensile strength, creeps strength and Young's modulus value. When the aluminium content is increased above $6 \%$ intermetallic compounds are formed. Beta stabilizing elements that come under an isomorphous group, are vanadium, molybdenum, tantalum, and niobium and the eutectoid forming group is manganese, iron, chromium, cobalt, nickel, copper and silicon. These two important properties have created interest in joining titanium and its alloys to stainless steel for application in aerospace, petrochemical and power generation industries $[1,2]$. Welding of stainless steel and titanium is very tough in view of the plain low dissolvability of iron in a titanium at room temperature. When the two materials are joined by normal fusion welding, it leads to the segregation of chemical components and development of tough and fragile intermetallic phases near the interface. It has been found that pure copper base alloys can be used to bond titanium to steel [3]. Also, titanium reacts easily and shapes intermetallic phases arranged as constant brittle and hard layers on interface limits. Direct DB between titanium and stainless steel show the improvement of chromium, iron and titanium base response products,

S. Rajakumar, srkcemajor@yahoo.com | ${ }^{1}$ Centre for Materials Joining and Research (CEMAJOR), Department of Manufacturing Engineering, Annamalai University, Annamalai Nagar, Tamil Nadu 608 002, India.

SN Applied Sciences (2019) 1:1128 | https://doi.org/10.1007/s42452-019-1189-6

Received: 11 March 2019 / Accepted: 28 August 2019 / Published online: 31 August 2019

SN Applied Sciences

A SPRINGER NATURE journal 
especially the course of action of $\mathrm{FeTi}, \mathrm{Fe}_{2} \mathrm{Ti}, \sigma, \mathrm{Fe}_{2} \mathrm{Ti}_{4} \mathrm{O}$ and $\mathrm{TiC}$ in the diffusion interface [4]. Therefore, the most suitable method to obtain strong joints of titanium to stainless steel appears to be the use of an appropriate intermediate material. Among these materials, copper is the most preferable metal since it doesn't form any detrimental intermetallic phases with iron and its melting point is much lower compared to steel.

Thirunavukarasu et al. studied diffusion-bonded Ti-6Al-4V and 304 SS using pure Ni of $200 \mu \mathrm{m}$ thickness as an interlayer in a vacuum, varying the holding time from 30 to $120 \mathrm{~min}$ in steps of $15 \mathrm{~min}$ using $4 \mathrm{MPa}$ load and $750{ }^{\circ} \mathrm{C}$ as bonding temperature. From this examination, they reached the uppermost tensile strength of $\sim 382 \mathrm{MPa}$ along with ductility of $\sim 3.7 \%$ for the joint took care of at an hour. Kundu et al. pointed out that copper interlayer cannot block the diffusion of $\mathrm{Fe}, \mathrm{Cr}$, and $\mathrm{Ni}$ to $\mathrm{Ti}$ side and $\mathrm{Ti}$ to $304 \mathrm{SS}$ side. Eroglu et al. expressed that $\mathrm{Cu}$-Ti base intermetallic phases have higher plasticity than the $\mathrm{Fe}-\mathrm{Ti}$ base intermetallics and affirmed that the $\mathrm{Cu}-\mathrm{Ti}-\mathrm{Fe}$ based intermetallics provide a good volume for plastic deformation and are set up to sufficiently halting microcrack propagation.

The present study is focused on DB of titanium and stainless steel using copper as an interlayer. The impact of holding time on the microstructure and mechanical properties of the joints has been explored.

\section{Experimental procedure}

The chemical compositions and mechanical properties of Ti-6AI-4V and AISI 304 are given in Tables 1 and 2. Titanium and stainless steel were received in the form of rolled plates having $5 \mathrm{~mm}$ thickness. From the base material square specimens of dimension $50 \times 50 \mathrm{~mm}$ were extracted. The joining surfaces of the specimens were surface prepared by standard techniques using few steps of grinding papers and polished on $1 \mu \mathrm{m}$ diamond suspension. The copper foil of $150 \mu \mathrm{m}$ thickness was used as an intermediate metal $[5,6]$. There were cut square profiles from the copper foil having $50 \mathrm{~mm}$ thickness. All specimens were then cleaned in $\left(\mathrm{CH}_{3}\right)_{2} \mathrm{CO}$ (acetone) and dried rapidly in air. The joined titanium and stainless steel specimens with implanted copper interlayer were kept in contact with a steel die. Thereafter, the samples together with the device were put into a vacuum furnace.
Table 2 Mechanical properties of base metals

\begin{tabular}{llll}
\hline Alloy & $\begin{array}{l}\text { 0.2\% yield } \\
\text { strength (MPa) }\end{array}$ & $\begin{array}{l}\text { Tensile } \\
\text { strength } \\
(\mathrm{MPa})\end{array}$ & $\begin{array}{l}\text { Elongation in } \\
50 \mathrm{~mm} \text { gauge } \\
\text { length (\%) }\end{array}$ \\
\hline Ti-6Al-4V & 880 & 950 & 14 \\
AISI 304 & 215 & 505 & 30 \\
\hline
\end{tabular}

The compressive stress of $14 \mathrm{MPa}$ along the longitudinal path was applied at room temperature. The holding times were $45,60,75,90$ and $105 \mathrm{~min}$ for $925^{\circ} \mathrm{C}$ in $10^{-5}$ torr vacuum. Bonding was carried out using a high-temperature DB machine, (shown in Fig. 1). After DB, the specimens were cut using wire-cut EDM, mechanically arranged at first with a grade 2500 abrasive paper [7] and $1 \mu \mathrm{m}$ diamond paste. Microstructural observations Ti-6Al-4V alloy side was etched using Keller's reagent $\left(85 \mathrm{ml} \mathrm{H}_{2} \mathrm{O}\right.$, $10 \mathrm{ml} \mathrm{HF}, 5 \mathrm{ml} \mathrm{HNO}_{3}$ ) and 304 ASS side was etched using $20 \mathrm{ml} \mathrm{HNO}_{3}, 60 \mathrm{ml} \mathrm{HCl}$. The chemical compositions of the phases were found in atomic percent using SEM with EDS investigation. The transverse microhardness profile of the DB joints was performed by Vickers microhardness tester under a load of $0.5 \mathrm{~kg}$ for a dwell time of $15 \mathrm{~s}$. The lap shear strength (LSS) and bonding strength (BS) of the bonded joints were assessed at room temperature. The measurements of the lap shear and ram tensile test samples are shown in Figs. 2 and 3.

\section{Results and discussion}

\subsection{Tensile properties}

From Fig. 4, it is found that the room temperature (RT) tensile properties (both LSS and BS) of the DB joints increases constantly during the time break from 45 to $90 \mathrm{~min}$ and drops at $105 \min [8,9]$, for a bonding temperature of $925^{\circ} \mathrm{C}$ and bonding pressure of $14 \mathrm{MPa}$. With the increase of holding time from 45 to $90 \mathrm{~min}$, the blending of mating surfaces enhances the room temperature properties of the DB joints, and additionally, offer some beneficial effect. Also, with a further increase in the holding time, over $90 \mathrm{~min}$, the reaction zone interaction at $\mathrm{Ti} / \mathrm{Cu}$ interface overcompensates for the reduction in the strength transcendently due to the development of intermetallics of a greater width which causes a sharp drop in the properties
Table 1 Chemical composition (wt\%) of the base metals

\begin{tabular}{lllllllllllll}
\hline Material & $\mathrm{Al}$ & $\mathrm{C}$ & $\mathrm{Cr}$ & $\mathrm{Fe}$ & $\mathrm{Mn}$ & $\mathrm{Ni}$ & $\mathrm{O}$ & $\mathrm{P}$ & $\mathrm{S}$ & $\mathrm{Si}$ & $\mathrm{Ti}$ & $\mathrm{V}$ \\
\hline Ti-6AI-4V & 6 & - & - & 0.25 & - & - & 0.2 & - & - & - & Bal & 4 \\
AISI 304 & - & 0.08 & 20 & $\mathrm{Bal}$ & 2 & 10 & - & 0.045 & 0.03 & 1 & - & - \\
\hline
\end{tabular}



sion bonding setup
Fig. 1 High-temperature diffu-

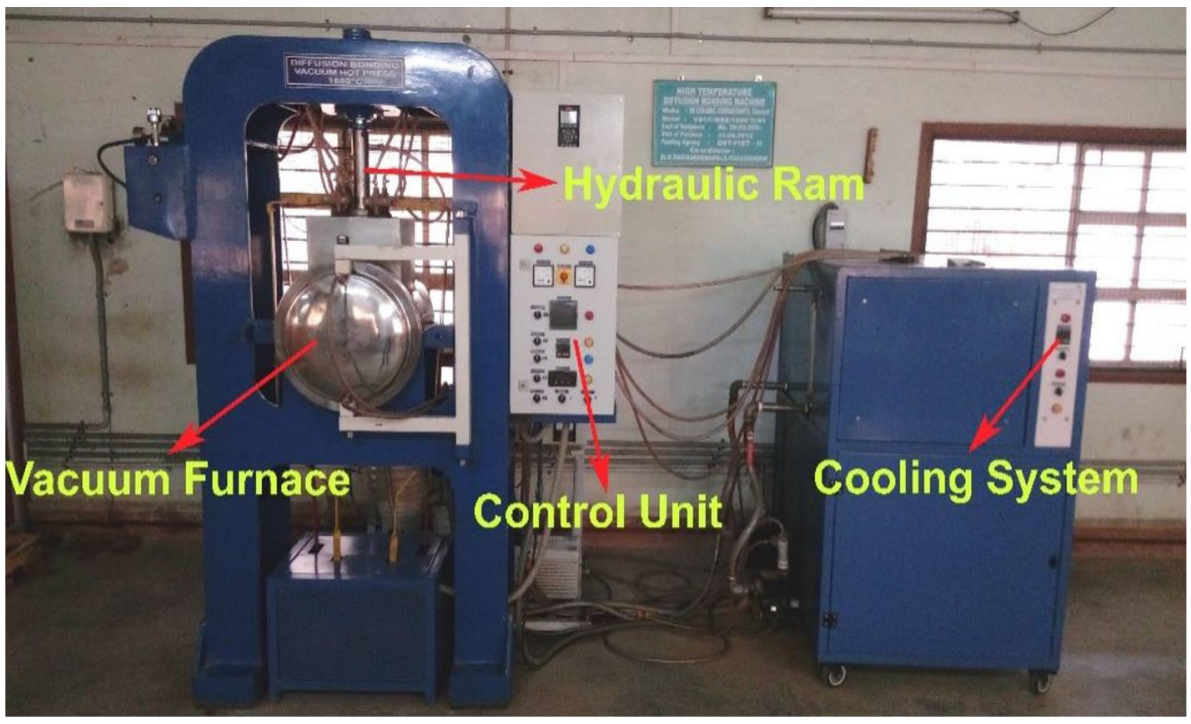

Fig. 2 Lap shear tensile test specimen details
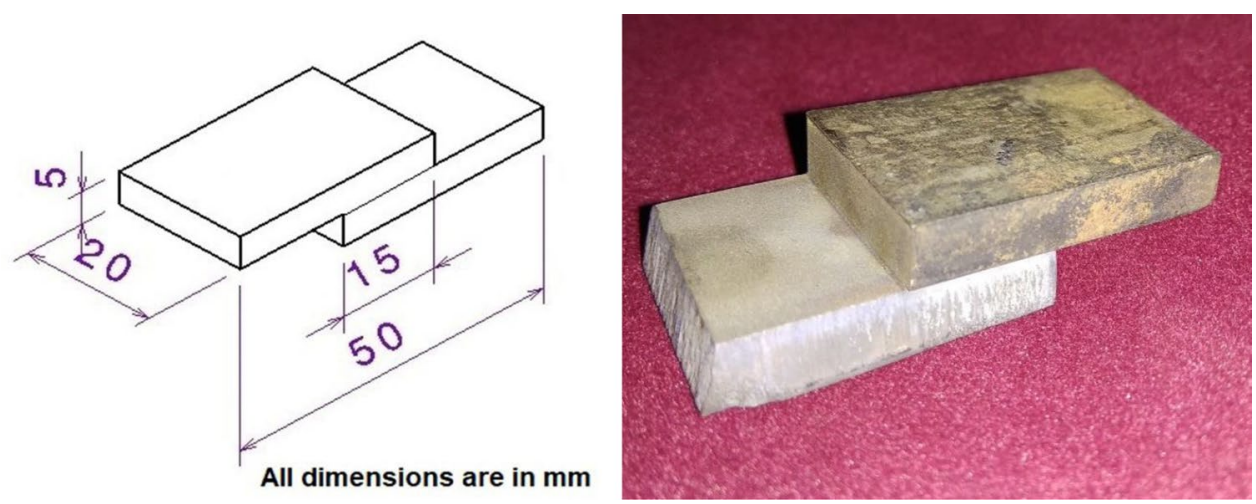

Fig. 3 Ram tensile test specimen details

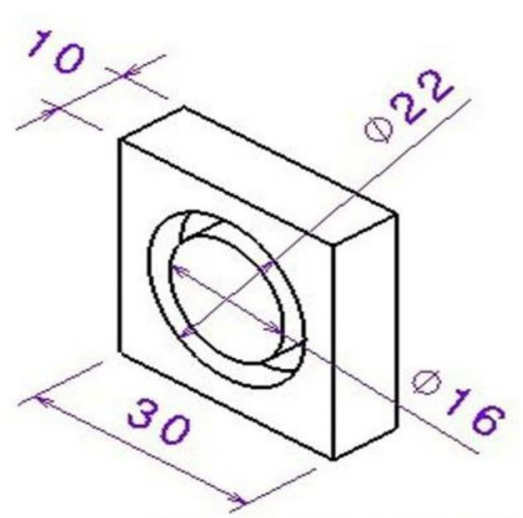

All dimensions are in $\mathbf{~ m m}$

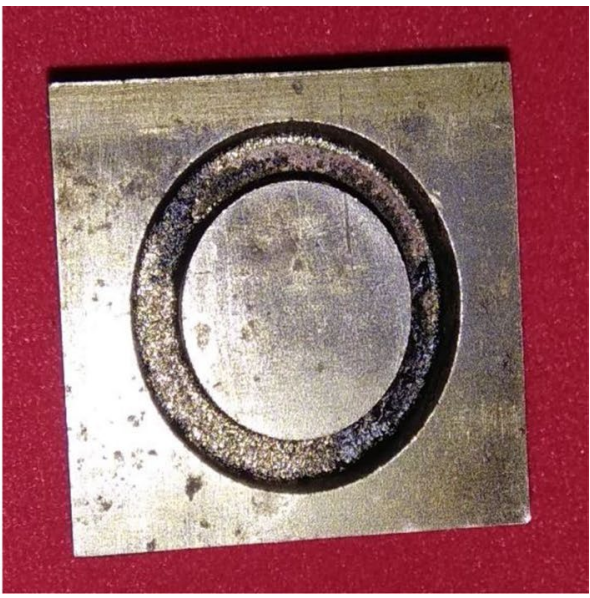

as it can't be overcome by the increase in combination of faying surfaces. Besides, this might be the conceivable reason for the tensile property conduct of the DB joints in achieving the optimal strength at $90 \mathrm{~min}$. The strengths of the DB joints are predominantly reliant on the Ti/Cu interfaces [10] than $\mathrm{Cu} / \mathrm{SS}$ interfaces, as the $\mathrm{Cu} / \mathrm{SS}$ interface displays complete solid-solution and the intermetallics at Ti/Cu interface exceptionally inclined to break because of embrittlement. Hence, an attempt has been made to draw the explanations for the strengths of the joints. It was found that $\mathrm{Cu}_{3} \mathrm{Ti}_{2}$ and $\mathrm{CuTi}$ phases were developed along with the $\mathrm{Ti} / \mathrm{Cu}$ interface during the time range of 


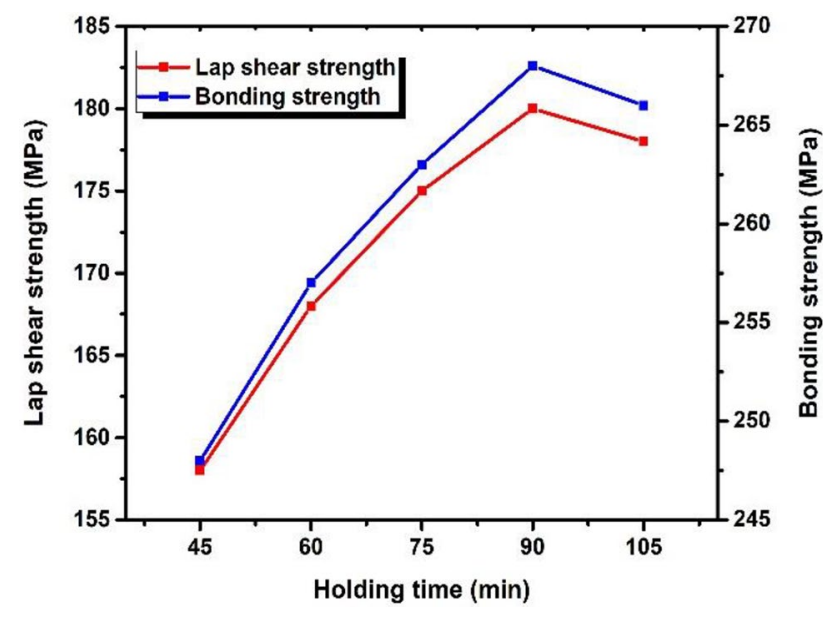

Fig. 4 Effect of holding time on strength

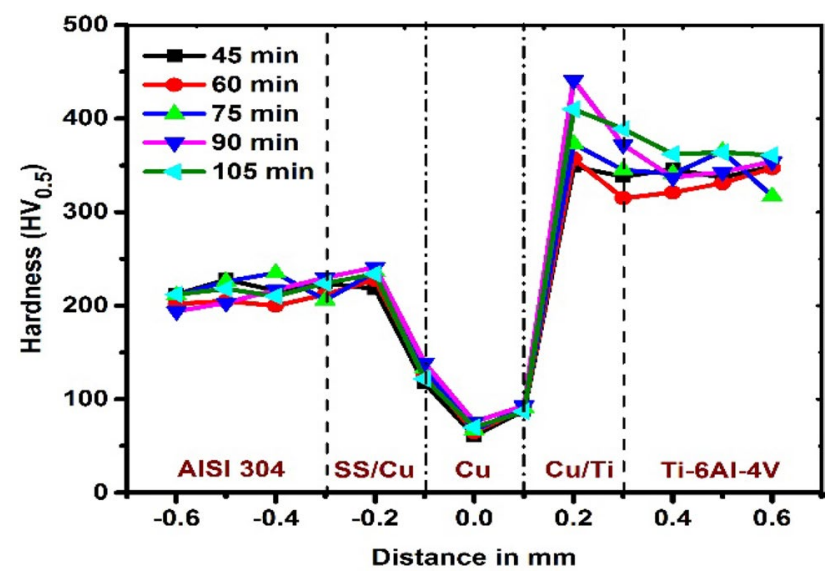

Fig. 5 Effect of holding time on microhardness

45-90 $\mathrm{min}$. Therefore, it can be inferred that the developments of $\mathrm{Cu}_{3} \mathrm{Ti}_{2}$ and CuTi phases simultaneously contribute to the increase in the bond strength for the time interval of 45-90 $\mathrm{min}$. For the bonds handled for $105 \mathrm{~min}$ the lowest value of strength was achieved in light of the large volume of intermetallic formation at the interface.

\subsection{Microhardness}

Figure 5 shows that both Ti and SS had a hardness of $\sim 350$ and $\sim 250 \mathrm{HV}$, though Cu's hardness was $\sim 75 \mathrm{HV}[11]$. Regardless of the selected bonding-time interval, hardness value improved from $\mathrm{Cu}$ to SS along the Cu/SS interface, and the observed hardness was $140 \mathrm{HV}$. Hardness value at first increased to a maximum value and then dropped toward $\mathrm{Cu}$ along with the Ti/Cu interface. The hardness of $\mathrm{Cu} / \mathrm{Ti}$ interface was $\sim 440 \mathrm{HV}$ for $90 \mathrm{~min}$, while $\sim 350 \mathrm{HV}$ for $45 \mathrm{~min}$. It was observed that the increase in the bonding time does not have an important effect on the hardness of $\mathrm{Ti}, \mathrm{SS}$, and $\mathrm{Cu}$. It was additionally observed that the $\mathrm{Cu} / \mathrm{SS}$ interfaces hardness increases toward Cu with the increasing bonding time, which is fundamental because of the diffusivity of atoms from the Cu matrix into SS.

\subsection{Microstructure}

Figure 6a reveals the occurrence of columnar grains along the rolling direction. Because $\mathrm{Ti}-6 \mathrm{Al}-4 \mathrm{~V}$ is a binary phase alloy, shown in Fig. 6 a reveals an equiaxed a (light color) phase with an intergranular $\beta$ (dark color) phase. In Fig. $6 \mathrm{~b}$ there are austenitic grains in the stainless steel micrograph. Figure 7 expressions that the interfacial microstructure of the DB samples at several holding time.

\subsubsection{Region I}

A strong region within the austenitic stainless steel was observed. In this region, the microstructure comprises a huge number of annealing twins. The development of the region I is basically identified with changes in
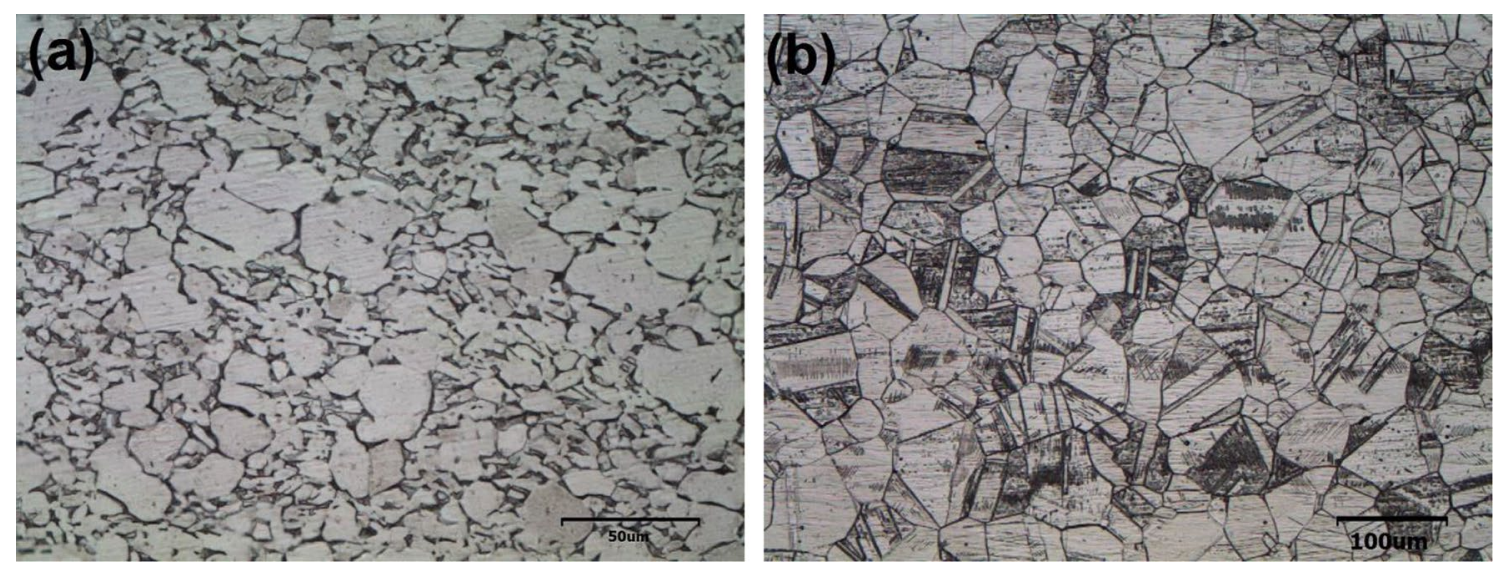

Fig. 6 Base metal micrographs a Ti-6Al-4V and b AISI 304 

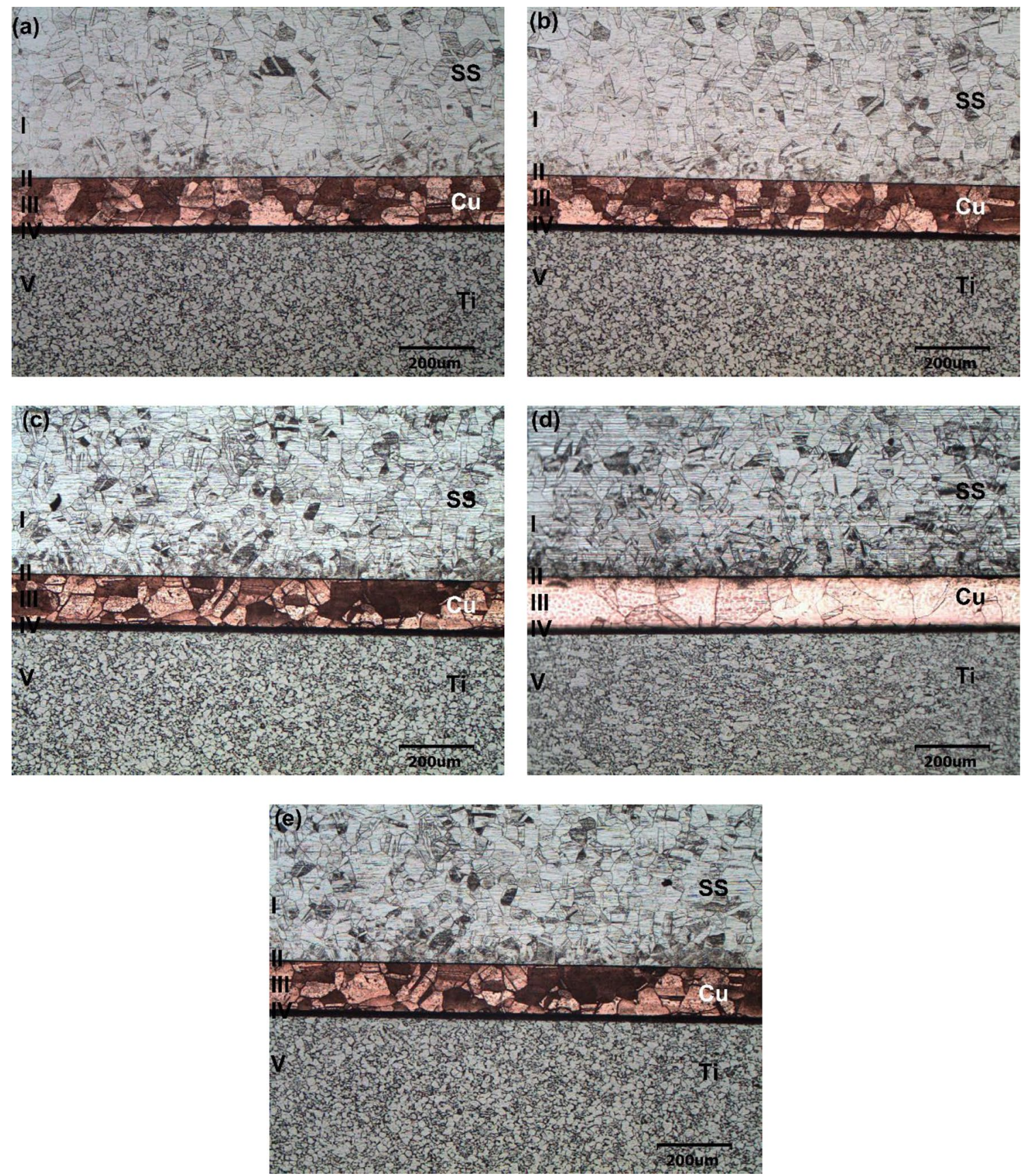

Fig. 7 Interfacial Microstructure of the DB samples a $45 \mathrm{~min}, \mathbf{b} 60 \mathrm{~min}, \mathbf{c} 75 \mathrm{~min}, \mathbf{d} 90 \mathrm{~min}$ and e $105 \mathrm{~min}$

composition. Considering that titanium is successful in making carbide and nickel is effective in forming austenite, the formation of this austenitic region appears to be solid. Outside of the five regions, there was no important change in the microstructures of the austenitic stainless steel and titanium alloy. However, some growth in the grain sizes of both sides was seen as the holding time increased.

\subsubsection{Region II}

This region is nearest to the austenitic stainless steel and shaped because of the interaction between copper and iron. So, this region consists of $\mathrm{Fe}-\mathrm{Cu}$ intermetallics. In addition, lesser amounts of $\mathrm{Cr}_{2} \mathrm{Ti}$ intermetallics were formed due to the higher chromium content in this region. 


\subsubsection{Region III}

The material composition of interlayer and base materials blended together is considered as Region III. The microstructure of the hot-rolled copper contains numerous small grains. Parallel straight lines stretching out crosswise over a significant number of the grains are called annealing twins.

\subsubsection{Region IV}

This region is essentially made out of titanium and copper. The primary phase in this region is $\beta$-Ti since a higher copper content would settle $\beta$-Ti at the holding time. Inside this region, compositional studies showed a decrease in the copper content and an increase in titanium content as the holding time increased. Furthermore, as indicated by the $\mathrm{Ti}-\mathrm{Cu}$ phase diagram, the development of $\mathrm{CuTi}_{2}$ intermetallic phase would likewise be normal inside this region, and the content of this intermetallic compound would increase as the holding time decreases.

\subsubsection{Region V}

This region created because of eutectoid transformation and consists of $\alpha$ and $\beta$-Ti. A liberal amount of $\mathrm{Fe}, \mathrm{Cr}, \mathrm{Ni}$, and $V$ around there results in a eutectoid transformation of the Ti alloy and, along these lines, the Widmänstatten morphology is established, in which bright $\beta$-Ti phase is injected in the shaded a-Ti matrix.

\subsection{SEM with EDS analysis}

Figure 8 illustrates the concentration profiles of elements over the steel to titanium by the method of the copper interlayer. Clearly, diffusion happens between the ASS to a titanium substrate $[12,13]$. The diffusion distance from steel to titanium is higher and in a little region of the element scattering curve, there is a level which specifies that intermetallic compounds are framed around there. Again, a significant part of the diffusion area indicates titanium with just a little content of additional elements. Ti is a faster diffusing species, and faster diffusion of Ti creates a large number of vacancies in its matrix, and thus promotes larger diffusional distance of $\mathrm{Fe}, \mathrm{Cr}$, and $\mathrm{Ni}$ in the Ti side.
The line profiles of the chemical species exhibit a number of concentration steps. Adjacent to the stainless steel side, $\mathrm{Cr}$ enrichment was observed for the bonded couples processed in the temperature of $925^{\circ} \mathrm{C}$. Adequate diffusion of $\mathrm{Ti}$ in the stainless steel side decreases the activity of $\mathrm{Cr}$ and diffusion takes place down the activity gradient rather than the concentration gradient. This implies that solid solutions are shaped around this region, which is for the most useful components for bonding.

In Fig. 9a it can be seen that the cleavage fracture [14, $15]$ along with the reaction layers which contain $\mathrm{CuTi}_{2}$ and CuTi intermetallics. The brittleness of these intermetallics has a determined effect on the LSS of the joints which are clearly confirmed. The fracture morphology associating to this fracture region indicated essentially river patterns, as seen in Fig. 9b. Tearing in the shear direction is also observed in the fracture surface [16]. Based on the EDS chemical analysis of the fracture surface, generally, fracture occurred in the CuTi phase.

\subsection{X-ray diffraction analysis}

XRD tests were performed on the fracture surfaces after accomplishing the shear test, as it is furnished in Fig. 10. The intermetallic compounds in the diffusion zone have been detected in the XRD technique. It is found that intermetallic phases of $\mathrm{Cu}, \mathrm{aTi}, \beta \mathrm{Ti}, \sigma, \mathrm{Cu}_{3} \mathrm{Ti}_{2}$, and CuTi were perceived from titanium and steel sides. It is significant that the diffusion of elements at the interfacial regions is the key parameters controlling the execution of the joint. At low holding time, $45 \mathrm{~min}$, thermal excitation of atoms at the interface was lacking due to which thorough mixing of the mating surfaces was absent. Increasing the time to $90 \mathrm{~min}$ was adequate to build up the diffusion at the interface and the mixture of the mating surfaces was accomplished.

\section{Conclusions}

(a) The copper interlayer cannot obstruct the diffusion of $\mathrm{Fe}, \mathrm{Cr}$, and $\mathrm{Ni}$ to $\mathrm{Ti}$ side and $\mathrm{Ti}, \mathrm{Al}$ and $\mathrm{V}$ to $304 \mathrm{SS}$ side. The best bond strength of $268 \mathrm{MPa}$ and LSS $180 \mathrm{MPa}$ has been reached for the diffusion joint treated at 90 min due to a better combination of the mating surface. 

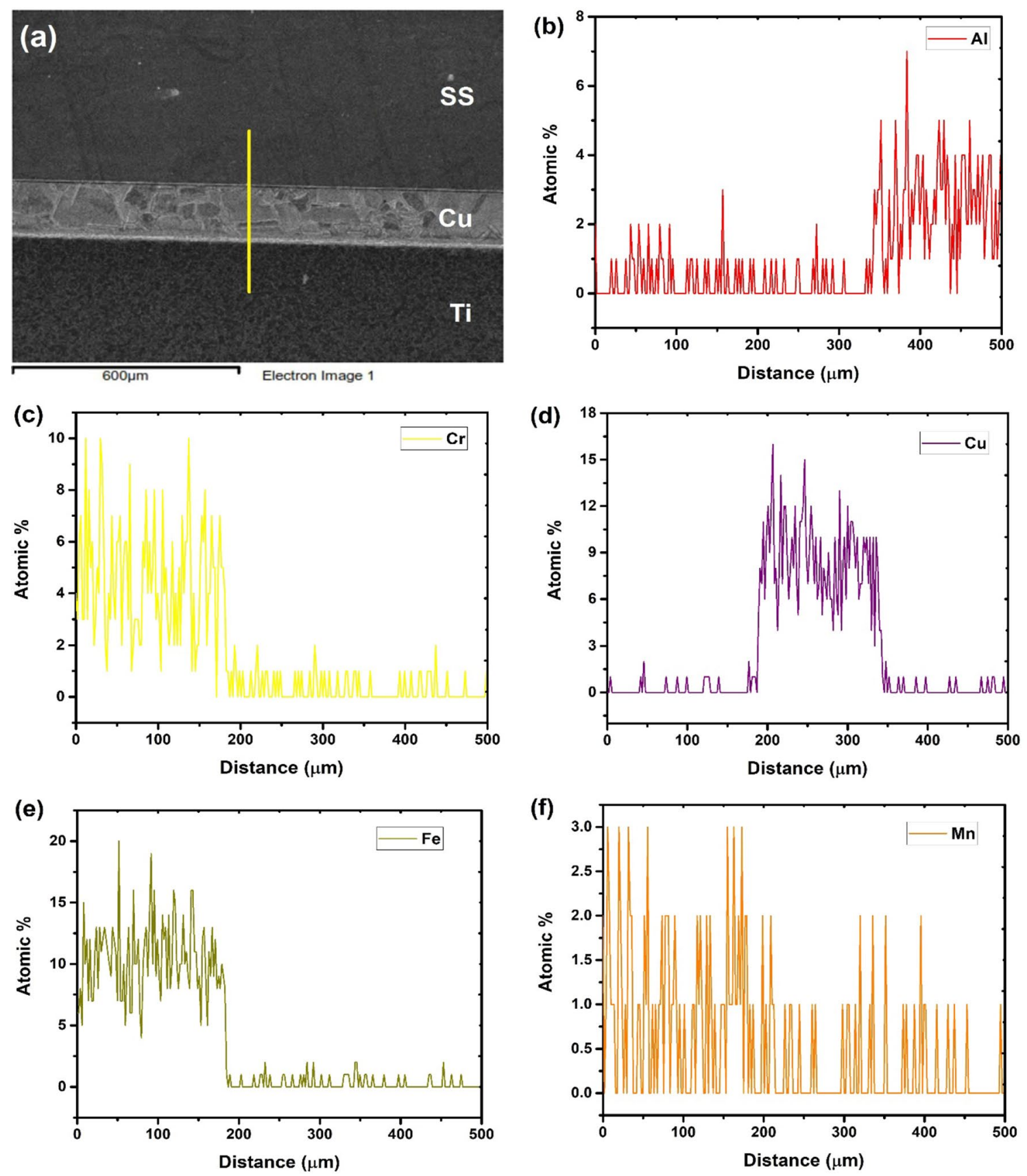

Fig. 8 Microstructural characteristics of DB joint processed for 90 min using 14 MPa pressing load at $925^{\circ} \mathrm{C}$ a SEM micrograph and $\mathbf{b}-\mathbf{j}$ EDS results

(b) Due to the close-packed FCC structure of these materials, the AISI 304/Cu interface is free from intermetallic compounds and a thin diffusion layer was uncovered for all the holding times applied during tests.

(c) Most vital structural changes occurred at the interface of $\mathrm{Cu} / \mathrm{Ti}-6 \mathrm{Al}-4 \mathrm{~V}$ as a result of the open crystallogra- phy of Ti matrix. An improvement in holding time caused a change in microstructure.

(d) The shear test result shows that the fracture of the bonded joints occurred at the titanium and steel side is attributed to the establishment of $\mathrm{Cu}_{3} \mathrm{Ti}_{2}$ and $\mathrm{CuTi}$ intermetallics in the titanium and steel side. 

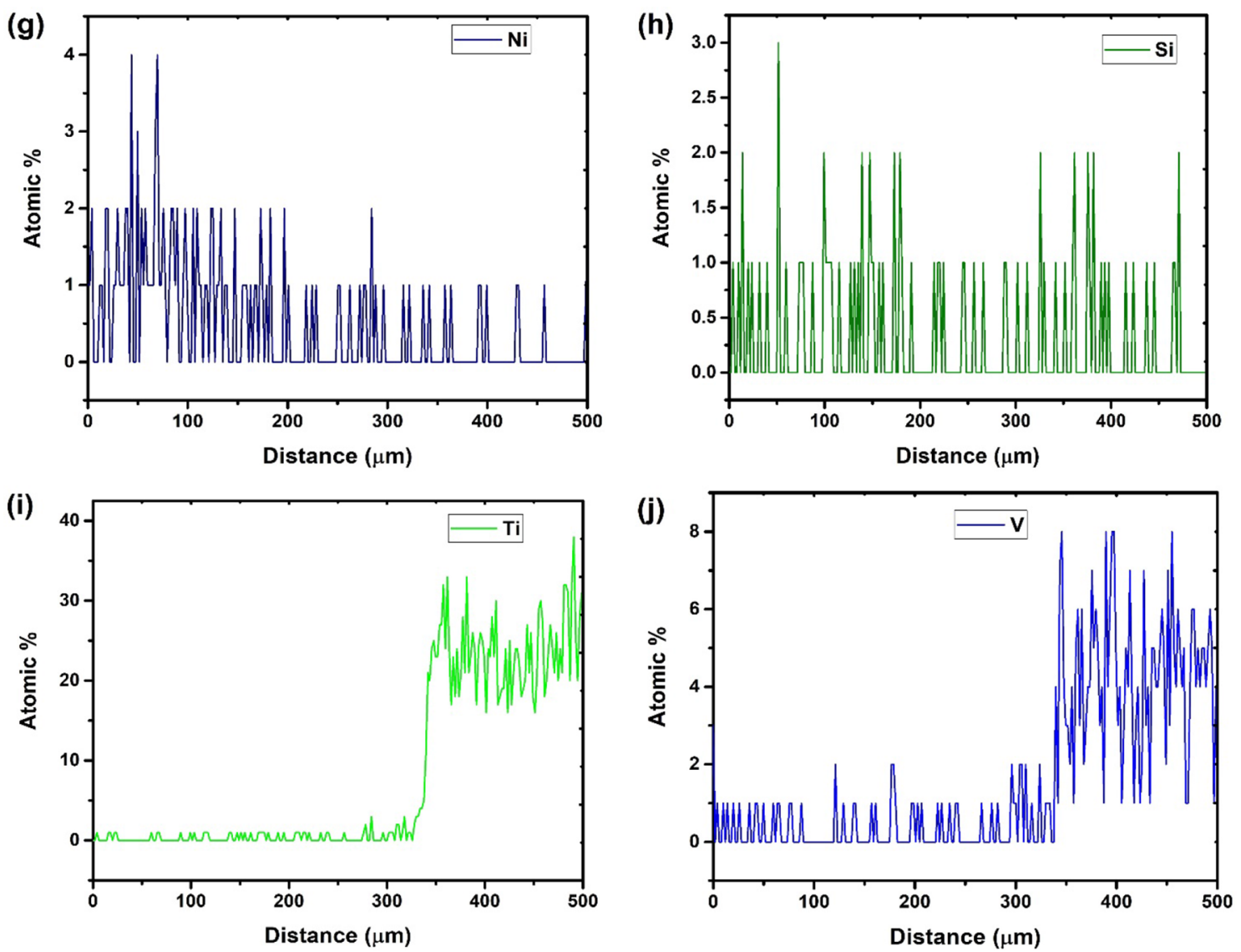

Fig. 8 (continued)
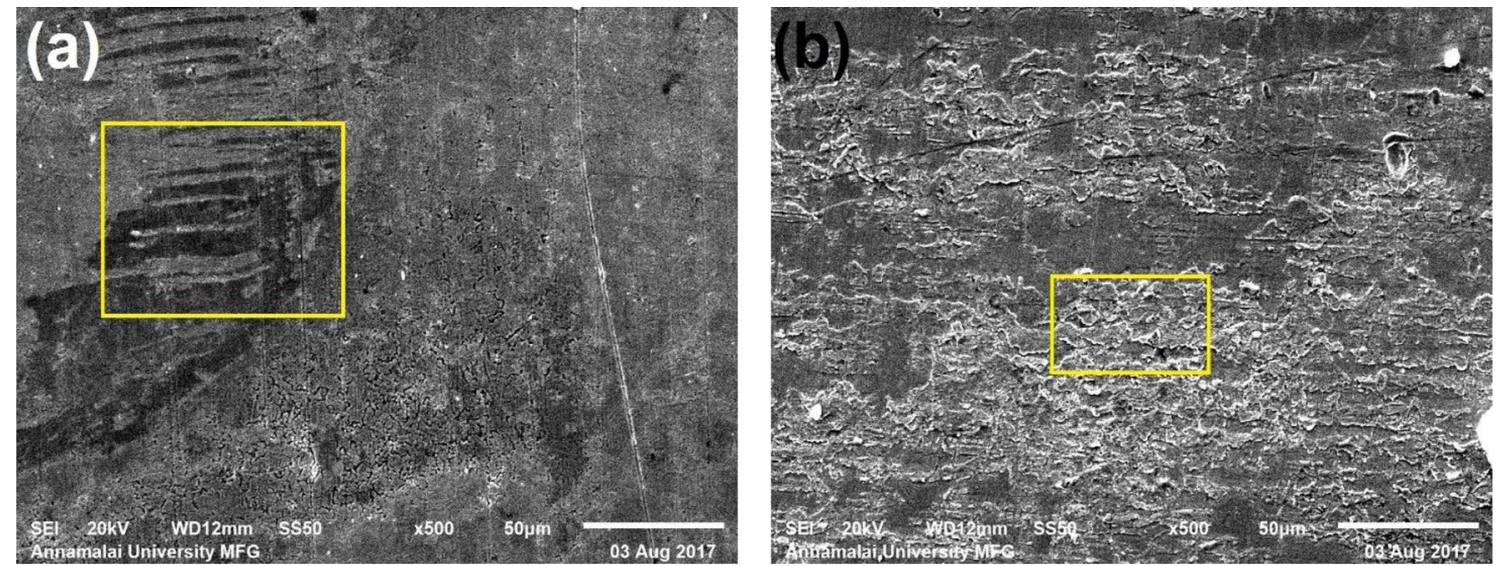

Fig. 9 The fracture surface of the specimens bonded at $90 \mathrm{~min} \mathbf{a}$ Ti side and $\mathbf{b}$ SS side 

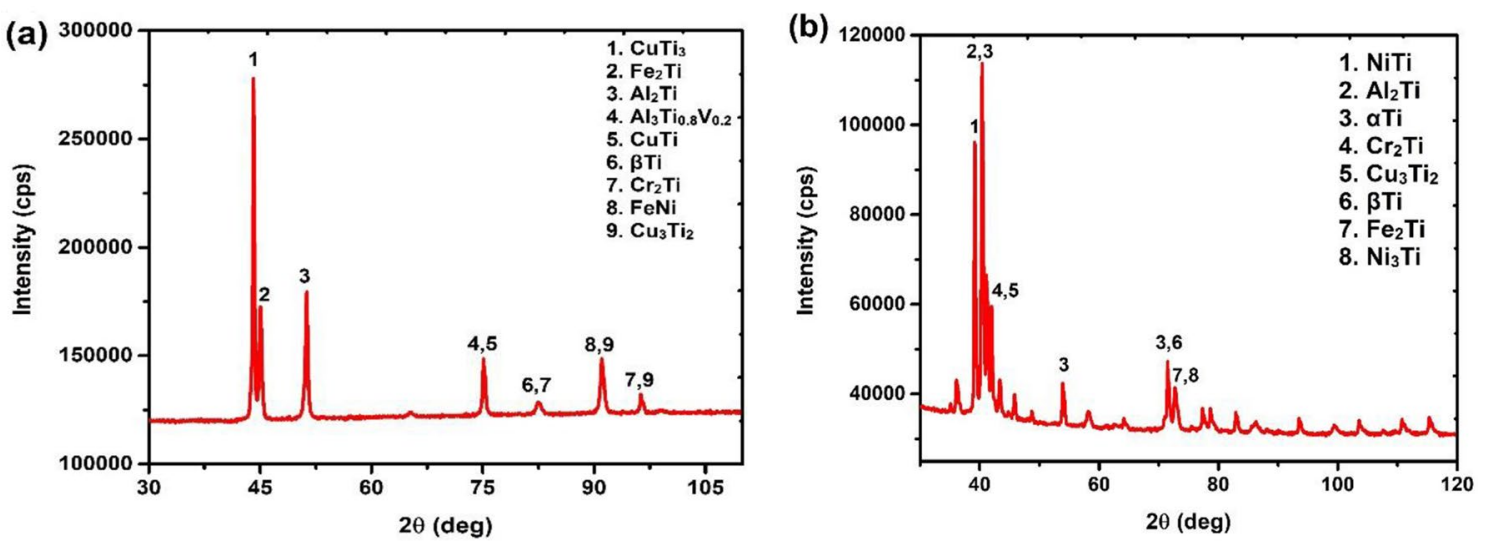

Fig. 10 XRD pattern of fracture surfaces of $\mathbf{a}$ Ti side and $\mathbf{b}$ SS side joint bonded at $90 \mathrm{~min}$

Acknowledgements The authors wish to record their truthful thanks to University Grants Commission (UGC), New Delhi for the financial provision rendered through the Major Research Project Scheme (MRPS) File No. 42-905/2013 (SR).

\section{Compliance with ethical standards}

Conflict of interest The authors declare that they have no conflict of interest.

\section{References}

1. Thirunavukarasu G, Kundu S, Mishra B, Chatterjee S (2014) Effect of bonding temperature on interfacial reaction and mechanical properties of diffusion-bonded joint between Ti-6Al-4V and 304 stainless steel using nickel as an intermediate material. Metall Mater Trans A Phys Metall Mater Sci 45:2067-2077

2. Zhong Z, Jung HC, Hinoki T, Kohyama A (2010) Effect of joining temperature on the microstructure and strength of tungsten/ ferritic steel joints diffusion bonded with a nickel interlayer. J Mater Process Technol 210:1805-1810

3. Elrefaey A, Tillmann W (2009) Solid state diffusion bonding of titanium to steel using a copper base alloy as interlayer. J Mater Process Technol 209:2746-2752

4. Kundu S, Ghosh M, Laik A, Bhanumurthy K, Kale GB, Chatterjee $S$ (2005) Diffusion bonding of commercially pure titanium to 304 stainless steel using copper interlayer. Mater Sci Eng A 407:154-160

5. Lee MK, Lee JG, Choi YH, Kim DW, Rhee CK, Lee YB, Hong SJ (2010) Interlayer engineering for dissimilar bonding of titanium to stainless steel. Mater Lett 64:1105-1108

6. Zeer GM, Zelenkova EG, Koroleva YP, Mikheev AA, Prokopy SV (2013) Diffusion bonding through interlayers. Weld Int 27:638-643
7. Yang G, Ma D, Liu L, Rong J, Yu X (2017) Thermal diffusion bonding of pure titanium to 304 stainless steel using aluminum interlayer. Chem Eng Trans 59:1045-1050

8. Mo D, Song T, Fang Y, Jiang X, Luo CQ, Simpson MD, Luo Z (2018) Review a review on diffusion bonding between titanium alloys and stainless steels. Adv Mater Sci Eng 2018:1-15

9. Rahman AHME, Cavalli MN (2010) Strength and microstructure of diffusion bonded titanium using silver and copper interlayers. Mater Sci Eng A 527:5189-5193

10. Thirunavukarasu G, Kundu S, Laha T, Roy D, Chatterjee S (2018) Exhibition of veiled features in diffusion bonding of titanium alloy and stainless steel via copper. Metall Res Technol 115:1-12

11. Szwed B, Konieczny M (2014) Influence of diffusion bonding parameters on the structure and properties of titanium and stainless steel joints with copper interlayer. J Achiev Mater Manuf Eng 67:21-25

12. Ozdemir N, Bilgin B (2009) Interfacial properties of diffusion bonded Ti-6AI-4V to AISI 304 stainless steel by inserting a $\mathrm{Cu}$ interlayer. Int J Adv Manuf Technol 41:519-526

13. Akbar AAA, Mahdi BS, Aluwi AJ (2019) Characterization of diffusion bonding of stainless steel AISI 316 and pure titanium sheets using copper interlayer. IOP Conf Ser Mater Sci Eng 518:1-13

14. Shuying BLIU, Kuan XU, Guangbao LIU, Congzong CAO (2013) The evolution characteristics and numerical analysis of diffusion bonding interface structure of Titanium alloy/Cu/Stainless steel. Rev Adv Mater Sci 33:224-231

15. Yongqiang $D$, Guangmin S, Lijing $Y$ (2015) Impulse pressuring diffusion bonding of titanium to stainless steel using a copper interlayer. Rare Met Mater Eng 44(5):1041-1045

16. Eroglu M, Khan TI, Orhan N (2002) Diffusion bonding between Ti-6Al $-4 \mathrm{~V}$ alloy and microduplex stainless steel with copper interlayer. Mater Sci Technol 18:68-72

Publisher's Note Springer Nature remains neutral with regard to jurisdictional claims in published maps and institutional affiliations. 